\title{
THE MANUFACTURER'S VIEWPOINT
}

\section{by Jerry L. Vaughan}

\section{Scott Engineering Sciences}

Historically, the development of audio-visual systems technology, as applied in education, has been characterized by no fewer than ten names or acronyms to describe the functional objectives of these systems. DAIRS, RAIRS, language lab, media center, and other names have been loosely used to describe the function of the systems employed in education. In reality, these names describe the functional mode of the system rather than the true function which is - to assist the learning effort. The nature of this "true function" statement im. plies that the system is made up of several parts which include (1) the instructor, (2) the student, (3) programming, (4) the hardware installation, and (5) the educational or behavioral objectives relative to the curricula.

It seems as if (1) the abundance of descriptive terminology, (2) lack of recognition for the role of the instructor in optimizing the total system performance, and (3) lack of understanding of the implementation of educational or behavioral objectives with electronic or mechanical systems, has precipitated the following conditions:

1. The true educational philosophy and objectives of the user and the methods that he must employ to achieve the objectives are obscured by the "state-of-the-art" technology that is FOR SALE.

2. Manufacturer's sales and marketing personnel have grown overly concerned with delivering a set of technical specifications and prices, then letting the user worry about the implementation of the hardware into the educational program.

It appears that this type of user/supplier relationship has resulted in many idle installations in which the user admittedly does not know how to fully employ the installation in an educational program. He literally bought what the supplier was selling.

This described market condition has apparently created the following situations:

1. Installations are being dismantled with other use being considered for facility. 
2. Other expenditures are planned, sometimes reflecting the same "state-of-the-art" influence, or in other instances a much less sophisticated system which the user, because of staff attrition and limited technical understanding, hopes to utilize complete$l y$, and over a longer period of timc.

These described market conditions have created the need for consultants who objectively study the educational philosophy and objectives of the institution, and then evaluate the supplier's technical specifications for compliance with the educational requirements.

With these conditions prevailing in the marketplace, it should be the natural evolution that the industry would search its soul for an evaluation of its product, the pretense under which it is sold, and its relationship to the educator and his objectives.

In the analysis of the names and acronyms that have been introduced to the educational complex - it appears that one has real meaning in terms of a common denominator or umbrella concept which is common to all educational applications. Conceptually, the principle, (and name) Information Retrieval is fundamental to all areas of education and involves (1) a method for storing information pertinent to the curricula, (2) a method for releasing the information when needed, and (3) a method for returning the information to storage after the need has passed. It is the type of information, its implementation, and method of implementation that determines the educational function of the installation.

Research indicates that educational function and technical specifications can and should be incorporated as part of the legal award document. Historically, the manfacturers of educational systems have been subjected to undue expense in satisfying unrealistic, even trivial technical specifications, when all educational functions and specifications had been satisfied.

The industry should be encouraged to seek better understanding of the implementation intent as related to the curricula and its behavioral objectives. If the industry does not insist upon these understandings, then it is subjecting itself to further profit reduction, and subjecting the user to further disillusionment with hardware systems.

Functionally, what can be expected of a hardware system? There are two questions that must be answered:

1. What can the hardware system do that the teacher cannot do?

2. What can the hardware system do that the teacher should not have to do?

In answering these questions, we essentially define the role of the 
instructor as a part of the system, and define the role of the hardware in its assistance to the learning effort.

By carrying the thought through, we find that there are basically three functions that the hardware system can perform:

1. The untiring drillmaster, offering repetitive or native information, which assists the student in learning a skill.

2. Testing and evaluation, either cumulative or paced for individualized learning on a cycle/recycle basis.

3. The creative or synergistic dialogue through which the students accept responsibility for learning through group identification.

In summary, it appears that in-spite-of a non-successful history of reliance on technical standards to accomplish educational objectives, educators are only slightly aware that a true cost or value analysis can be achieved only when a hardware system is designed to educational function specifications. As a result, most future buying plans reflect the same state-of-the-art influence as seen in the last decade. This is shameful since functional identification requires only a little thought and planning for the future. 